\title{
The Research of Administrative Mode's Leading Capacity Exit
}

\author{
Lihua Liang ${ }^{1,2}$ \\ ${ }^{1}$ Institute for Innovation and Development, Tsinghua University, Beijing, China \\ ${ }^{2}$ Institute of Economics, Tsinghua University, Beijing, China
}

\section{Email address:}

lianglihua53@163.com

\section{To cite this article:}

Lihua Liang. The Research of Administrative Mode's Leading Capacity Exit. Science Innovation. Vol. 5, No. 5, 2017, pp. $325-330$. doi: 10.11648/j.si.20170505.25

Received: June 30, 2017; Accepted: August 4, 2017; Published: August 17, 2017

\begin{abstract}
In order to solve the structural problems which exist in the process of economic development in China, it is the necessary choice to push the structural reform of the supply front. Based on analysis of the status quo of economic and social development in China, we should try our best push transformation, innovation and reformin the process of the structural reform of the supply front, it will form a socialist market economic system, correctly handle the relationship between the government and market, really realize the sus-tainable development of economic and social.
\end{abstract}

Keywords: Administrative Way, Capacity Exit, Analysis

\section{行政方式主导产能退出的研究}

梁丽华 ${ }^{1,2}$

1创新发展研究院, 清华大学, 北京, 中国

2社科学院经济学研究所, 清华大学, 北京, 中国

邮箱

lianglihua@163.com

摘要：为解决中国经济发展过程中存在的结构性问题，推进供给侧结构性改革是引领经济“新常态”的必然选择。基于 中国经济社会发展的现状分析，推进供给侧结构性改革必须做好“转型、创新和改革”方面的工作，才能真正形成社会 主义市场经济体制, 正确处理好政府和市场的关系, 实现经济社会的可持续发展。但改革过程中要面临经济运行困难、 财政收支压力和制度改革阻力等挑战, 需统筹安排、审时度势、有序进行, 从要素结构、供给者结构、产业结构着手 重点推进供给侧改革。

关键词: 行政方式, 产能退出, 供给侧研究

\section{1. 引言}

过去30年, 我国主要依靠扩大投资需求来促进经济快 速增长[1]。在经历了前期经济高速扩张以及经济刺激政策 所导致的产能大规模扩张后, 中国当前正面临着内外需不
振、大量产能无法消化的局面, 产能过剩问题已经开始严 重阻碍中国的产业结构调整和经济的良性发展, 成为当下 中国经济最亟待解决的关键问题[2]。

在面临全球经济危机，整体经济下行的大背景下， 政府仅仅依靠需求侧方式来促进中国经济的发展, 即所 谓的扩大内需或扩大外需, 总体效果并不理想。而且中 
国经济现在已经进入到一个新老动力交替的新阶段，依 靠传统的增加低成本要素投入来驱动经济社会增长的旧 方式, 变得越来越艰难。所以继续采取旧方式来促进经 济的方式不仅会造成大量资源浪费, 而且效率和质量都 不会太好。在这样的环境下，政府想继续通过扩大财政 支出, 以此来填补传统产业过剩产能的需求, 从而拉动 经济增长的效率也在衰减。这样的管理方式产生了大量 的过剩产能、如房地产库存、银行不良资产、股市暴跌 和地方政府债务等问题 [3]。

2015年11月 10 日，国家主席习近平在中央财经领导 小组第 11 次会议上首次提到了“供给侧改革”, 即“在适度 扩大总需求的同时, 着力加强供给侧结构性改革, 着力 提高供给体系质量和效率，增强经济持续增长动力”。11 月 18 日，习近平主席在APEC会议上再次强调了“供给侧 改革”并指出“要解决世界经济深层次问题, 单纯靠货币 刺激政策是不够的, 必须下决心在推进经济结构性改革 方面做更大努力, 使供给体系更适应需求结构的变化。” 可见，“供给侧改革”是我国当前形势下寻求经济新增长 的必然选择, 是引领我国经济持续健康发展的关键 [4]。

面对当前中国经济社会环境不断发生变化, 同时这种 变化会不可避免的传导到各个领域, 经济周期的循环导致 行业结构和产业结构也在发生变动。虽然当前经济下行的 原因从表面上看仅仅表现为内需和周期变动, 但本质上是 深层次的结构性和体制性问题 [5]。

本轮去产能是内部结构性失衡和外部需求疲软叠加 的后果, 既无法通过短期快速的需求回升达到过剩产能的
出清, 也无法通过迅速的扭转利益格局改善结构性失衡, 性质复杂, 是否继续采取行政方式主导产能退出的老路我 们要认真分析。

本文首先分析了过去五轮行政性去产能的政策和 结果, 并且对继续采用行政性去产能的可行性进行了分 析, 发现只有推进供给侧结构性改革才是可行并且必须 的路径; 然后提出了采用供给侧结构性改革来推动去产 能是最佳的方案，只有深化供给侧结构性改革，做好“转 型、创新和改革”方面的工作，才能真正意义上的做好 去产能的任务; 最后给出了政策建议, 继续发展社会主 义市场经济体制, 更好的正确的处理好政府和市场的关 系, 才能实现经济社会的可持续发展, 完成去产能的工 作。

\section{2. 过去五轮行政性去产能分析}

\section{1. 行政方式去产能政策总结}

自2003年以来中央不断发文着手处理过剩产能, 中央 发布一系列去产能的文件。本文归纳为 5 轮去产能阶段, 不同阶段有不同的主题特点。2003-2006年限制盲目投资; 2006-2009年主抓结构调整；2009-2013年重点淘汰落后产 能; 从2013年10月开始产能控制; 从2015年开始重点放在 供给侧改革。同时, 中央发布一系列配套去产能的文件, 涉及行业涵盖钢铁、水泥、平板玻璃、煤化工、风电设备、 多晶硅、汽车等 (见表1)。

2003-2006

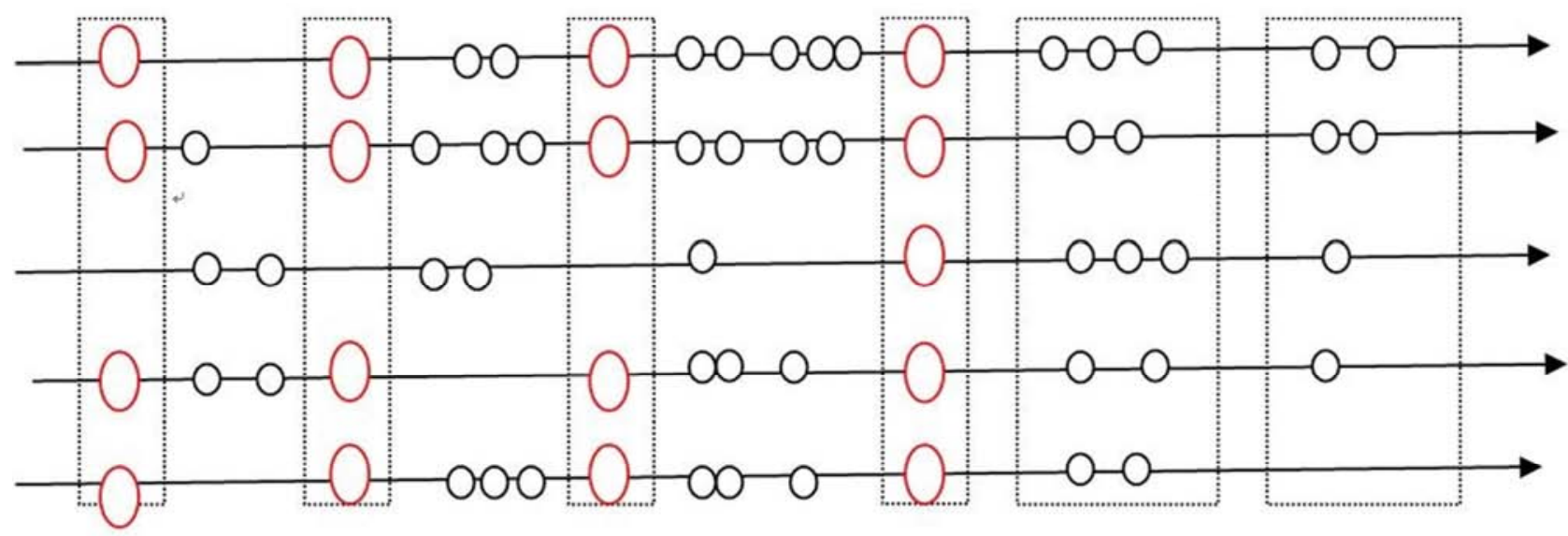

国务院发布的指导政策

○工信部, 发改委等国务院委发布的政策

图1 中国 “去产能” 的发展历程。

同时，中央发布一系列配套去产能的文件，如2003 年出台了《制止钢铁电解铝水泥行业盲目投资若干意见的 通知》, 2006年出台了《国务院关于加快推进产能过剩行 业结构调整通知》，2009年出台了《关于抑制部分行业产 能过剩和重复建设引导产业健康发展的若干意见》, 2013
年出台了《国务院关于化解产能严重过剩矛盾的指导意 见》, 2015年以后发改委等部门出台了一系列关于供给侧 改革的诸多文件, 五轮行政手段去产能涉及行业涵盖钢铁、 水泥、平板玻璃、煤化工、风电设备、多晶硅、汽车等 (见 表1）。 
表1中国过去五轮去产能政策分析。

\begin{tabular}{llll}
\hline 时间 & 去产能阶段 & 政策文件 & 涉及行业 \\
\hline 2003 & 限制盲目投资 & 《制止钢铁电解铝水泥行业盲目投资若干意见的通知》 & 钢铁、电解铝、水泥、汽车等 \\
2006 & 主抓结构调整 & 《国务院关于加快推进产能过剩行业结构调整通知》 & 钢铁、电解铝、电石、铁合金、焦炭、汽车 \\
2009 & 重点淘汰落后产能 & 《关于抑制部分行业产能过剩和重复建设引导产业健康 & 钢铁、水泥、平板玻璃、煤化工、风电设备、多 \\
2013 & 菁始产能控制 & 《国务院关于化解产能严重过剩矛盾的指导意见》 & 晶硅、船舶等6个行业 \\
$2015-$ 至今 & 供给侧改革 & 发改委等部门关于供给侧改革的诸多文件 & 水泥、电解铝、平板玻璃、船舶 \\
\end{tabular}

\section{2. 行政方式去产能效果不佳}

从中国政策实施的效果来看, 难以根本上治理产能过 剩, 反而会加剧市场波动。不当的产业政策, 如不合理的 产能淘汰与战略新兴产业补贴政策，更是造成了目前“扶 大限小”、以及光伏过度投资的状况。

同时由政府主导的兼并重组模式，导致了大量地方政 府主导非市场导向的兼并重组。如河北钢铁集团、山东钢 铁集团的组建，地方政府出于获得更多政策扶持的考虑而 将本地企业拼凑起来, 除了地区垄断能力得到提高, 这些 举措对于核心竞争力提升有限, 反观多数兼并重组企业非 但没有缩减产能反而扩大产能。

行政方式主导的去产能造成产能过剩局面。通常来说 如果一个行业的产能利用率低于75\%, 即判定该行业出现 产能过剩, 目前我国钢铁、煤炭、水泥、建材等行业的产 能过剩已经属于“绝对过剩”, 严重低于 $75 \%$ 。另外中国过 剩产能变化呈现趋势上涨形态。钢体行业 (粗钢) 呈逐渐 上升趋势, 其他产能过剩行业产能如有色, 水泥, 原煤, 玻璃等也是出现不同程度的增长。行业盈利急剧恶化, 亏 损面不断扩大。目前国内煤炭、钢铁和有色金属行业亏损 局面严重。过剩产能行业大都是国有企业, 而国有企业人 员负担沉重, 目前煤炭、钢铁和有色行业总就业人数超过 1100 万人, 其中约 440 万来自于煤炭行业, 420 万来自于钢 铁, 电解铝行业相对较少, 仅为 30 万人。过剩产能行业大 多是支柱产业, 产能过剩对经济影响较大, 对地方政府财 政收入恶化，造成经济下行压力增大。

\section{3. 继续采用行政方式主导去产能的可行性分析}

\section{1. 行政方式去产能阻力分析}

中央政府和地方政府之间存在着利益博弯的关系。在 去产能的过程中, 中央的决心会远远大于地方政府的积极 性。随着市场经济的发展和财政分权体制的形成, 中央和 和地方的关系变得博弯, 地方政府不仅是中央政府在本地 区的利益代表者, 同时也是地方自身利益的代表者。

从目标上来说，中央政府制定政策的出发点在于最大 化公共利益, 追求的是经济平衡、社会平稳, 对经济有着 更长远的考虑; 而地方政府更加注重所辖区域和自身的利 益

由于地方的绩效考核关系到官员的升迁问题，某些 当地官员存在短视的动机, 盲目的追求地区短期GDP的 增长, 一方面这些产能过剩的企业是纳税贡献者, 去产 能会一定程度上减少地方财政收入，不利于地方财政的 收入增长以及地方官员自身政绩的提升; 另一方面去产
能会涉及到地方的员工就业等系列问题，不利于地方的 社会稳定。

所以在关乎利益的问题上，中央政府和地方政府之 间存在着利益博峦。地方政府由于对经济增长数据的竞 争, 存在盲目跟风现象。尤其是在基础设施建设和房地 产行业迅猛发展的时期, 为了创造地区的GDP, 大幅度 推动了中上游行业的同质性投资, 为之后的产能过剩埋 下伏笔。

虽然中央对地方政府有监督的作用，但是由于存在 委托代理问题, 一些地方政府为了自身的利益, 会利用 信息不对称的优势来规避这种监督行为。比如在中央政 策紧时, 经济不好的时候关闭过剩产能, 而过剩产能的 压力问题一有放缓, 地方政府就会准许企业复产。这种 利益的博峦相当程度上阻碍了去产能的进程。比如在贯 彻执行中央的政策命令时, 对于不利于自身利益的, 地 方政府往往会陷入冈徒困境，在执行中央去产能的政策 时消极散漫, 反而寄希望于其他地区的地方政府大力去 产能, 从而使自己辖区的企业能享受全国去产能带来的 收益。

地方政府和地方国有企业存在利益共同体关系。地方 政府往往引导地方国的投资, 从而为当地创造财政收入和 税收。这种双方利益的绑架在一定程度上造成了低水平无 效的重复投资，这是造成过剩产能的关键问题所在。而当 行业不景气时, 国有企业大面积亏损时, 地方政府一方面 提供财政补贴, 另一方面以自身的信用背书, 给企业不断 贷款, 这严重阻碍了地方过剩产能企业的退出。同时, 在 去产能的过程中, 地方政府常常会行政主导的方式来干预 企业间的兼并重组, 保护所辖地区的企业不被其他地区企 业兼并, 阻碍了过剩产能的出清。

\section{2. 对未来创新产能目标不明确}

从外部环境来看, 全球化红利变成了全球再平衡的压 力, 还充斥着TPP和TTIP的压力, 再加上劳动力比较优势 的丧失, 仅仅依靠出口的方式已经不可能解决中国的过剩 产能问题。

从经济周期来看，2016年处在工业化后期，下一个阶 段是高加工与服务经济阶段。这意味着, 站在现阶段看未 来的经济发展前景并不明朗。

创新转型会是未来经济发展的引擎, 而创新转型的行 业主要是新兴服务业和高端制造业。虽然创新转型能激发 部分新的需求, 但对旧需求作用甚微。虽然创新转型有利 于扩大总需求, 但并不会扩大对对重化工业、钢铁和建筑 业等传统过剩产能的继续需求。 


\section{4. 供给侧结构性改革主导下的去产能分析}

供给侧结构性改革的核心是放松管制、释放活力、让 市场机制发挥决定性作用, 从而降低制度性交易成本，提 高供给体系的质量和效率，提高投资有效性。中国推行的 供给侧改革, 是着眼于中国发展实际, 更侧重提升经济增 长的效率和企业长期发展的活力, 来实现经济长期发展的 持续平衡。

\section{1. 供给侧结构性改革的经济学意义}

“供给侧”（supply-side）经济学派的开端, 19世纪初 法国著名经济学家让·萨伊 (Jeanb B.S ay) 提出并发展的 “萨伊定律”[6]。按照萨伊的论述, 一般来讲, 生产者在完 成产品的最后一道工序之后, 害怕产品滞留手中会丧失其 原本的价值, 于是总是急于将产品出售; 同时, 他也同样 急于把出售产品所得到的货币花光, 因为货币的价值也是 极易流失的。由于出手货币唯一可用的办法就是买东西, 因此, 一种产品的生产会为其他产品开辟销路 [7]。

然而，1029-1933年，美国爆发经济危机，并引发了 全球性的经济衰退, 即 20 世纪初著名的“大萧条”。到20世 纪30年代, 当时几乎所有的资本主义国家均出现了购买力 不足和供给严重过剩的情况。

在这一背景下, 英国著名经济学家约翰·凯恩斯提出 了“凯恩斯定律”并发起了经济学研究领域和研究范式颠 覆性转变的革命 [8]。凯恩斯认为, 由于边际消费倾向递减、 资本边际效率递减以及货币的流动偏好需要和利率下降 刚性等因素的存在, 导致了社会有效需求的不足, 因此, 针对商品和劳务总需求不足的情况, 应通过政府支出, 减 税和货币扩张等措施来加以解决。在宏观调控中以“需求 侧” (demand-side) 为主要视角的凯恩斯主义在引发“凯恩 斯革命”的同时，几乎全盘否定了“供给侧的早期代表”。

随着20世纪70年代“滞胀”（stagflation）局面的出现， 经济学界发现, 这种新的经济危机现象一方面导致经济增 长放慢甚至停滞, 并引发大量的失业, 另一方面则进一步 加剧了通货膨胀, 对凯恩斯的“需求干预”主义提出了严峻 的挑战。

供给学派认为, 政府行为的过度扩张将造成私人活动 的被排挤, 而由于私人活动的效率要远高于公共活动的效 率, 因此, 缩减政府活动水平, 规范政府行为, 限制政府 的不起当敢于是必须的。

在政治层面, 以“减税”为核心的里根经济学以及以 “私有化改革”为重点的撒切尔主义成为“供给侧”观点在 国家宏观政策中实践的典型[9]。

\section{2. 供给侧结构性改革的现实背景}

在中国“供给侧结构性改革”中, “供给侧”是改革切入 点, “结构性”是改革方式, “改革”才是核心命题, 内在地 体现出“转型是目标、创新是手段、改革是保障”的逻辑关 系[10]。

里根经济学是为了解决当时西方社会普遍面临的滞 胀而提出的改革, 内容主要是一些减税政策和产业政策, 并且这些改革政策都主要是针对企业, 其目的是为了减轻
企业负担，让企业更愿意投资和扩大生产。

然而, 中国的供给侧改革所面临的环境与当时的西方 社会完全不同。首先, 中国是在新常态下进行的, 其目标 是为了发展知识密集型经济以走出中等收入陷阱。

与此同时, 中国的供给侧改革同时也面临着大量的产 能过剩和僵尸企业[11]。产能过剩和僵尸企业的存在并非 因为劳动力成本过高, 而在于其所提供的产品属粗放型 (即技术含量非常低), 已不适合因经济社会发展和人均收 入不断提高的市场需求, 而劳动力成本提高的根本原因还 在于劳动力从过剩转向短缺, 这是中国经济新常态的基本 特征。

因此, 中国的供给侧改革绝不能从里根经济学中寻找 答案, 更不能用修改劳动合同法的办法来保护企业 (特别 是僵尸企业) [12]。

\section{3. 供给侧结构性改革的理论内涵}

供给侧结构性改革有其内在的逻辑结构和理论体系。 所谓供给侧改革, 就是从供给生产端入手, 通过供给结构 的调整、优化, 不断降低企业的制度性交易成本( 包括各 种税费、社会保障成本、融资成本等), 促进投资者更有 效地进入各生产领域等改革措施, 最大限度地释放生产力, 提高全要素生产率, 提升企业竞争力, 创造新的经济增长 点, 恢复经济活力, 实现经济社会可持续发展。

习近平总书记指出, “推进供给侧结构性改革, 是一 场硬仗。要把握好“加法”和 ‘减法”、当前和长远、力度和 节奏、主要矛盾和次要矛盾、政府和市场的关系”（习近 平，2016）。这“五对”关系强调的就是要把握好改革的起 点、重点、难点、焦点和着力点, 做好“去产能、去库存、 去杜杆、降成本、补短板”的工作[13-15]。

\section{4. 供给侧结构性改革的实践路径}

总之而言，我国当前的供给侧结构性改革面临的环境 和里根政府进行基于供给学派的经济政策所在的政策背 景、政策目标和政策手段方面存在根本性的区别。所以, 中国在实施供给侧结构性改革中, 应当厘清理论上与实践 中的误区, 不能照搬美国的历史经验。经济和社会环境不 同, 当然政策出台的药方也不会相同, 这也是中国实施供 给侧结构性改革的重要关键。

通过分析, 我国的供给侧结构性改革的路径既有短期 路径, 也必须具有长期路径。

从短期来看, 要抓好以“去产能、去库存、去杜杆、 降成本、补短板”为核心的五大战术任务; 即通过短期对 资源的合理配置, 积极并快速的解决产能结构性过剩问题, 淘汰部分落后产能; 帮助过剩产能企业降低成本, 从而进 一步减少阻碍过剩产能和企业活力的制度性因素以及政 府对过剩产能企业的行政性干预, 充分发挥过剩产能企业 微观主体的主观能动性, 达到淘汰落后产能, 最终促进有 效供给[13]。

从长期来看, 供给侧结构性改革要以转变经济增长方 式为目标, 特别是要转变发展理念, 落实“创新、协调、 绿色、开放、共享”的五大发展理念。要建造以创新为驱 动的增长模式, 即通过发挥创新对拉动经济的拉动作用, 
重视创造创业基因的发挥, 为创新创业提供良好的制度和 经济社会环境, 发挥“互联网+”的平台型作用, 努力建设 和发展物联网技术和应用, 为教育和科学研发提供必要的 资金和基础设施服务，更好的为创新创业提供丰富的土壤。 与此同时，通过对外开放增强全球配置资源能力，深 度融入全球创新产业链、创新价值链、物流链。全面建设 以创新为核心的新的经济发展模式, 做到创新和经济总量 与经济质量的三重增长。

\section{5. 结论和政策建议}

\section{1. 发挥市场和法治的根本作用}

充分发挥市场在资源配置中的决定性作用, 大力改革 市场经济的宏观框架和微观基础, 这是解决当前我国产能 过剩问题的核心所在。在做好稳增长和防风险的同时, 继 续加快简政放权、财税改革、国企改革、服务业放开、利 率汇率市场化、资源要素价格市场化等一系列领域的改革。

充分发挥市场经济本质是法治经济的力量。充分理解 居民的消费行为、企业的投资生产行为以及财产权是自主 决策并受到法律保护。所以政府发挥平台型作用, 最终还 是要通过市场机制来引导微观主体的经济行为, 从而达到 去产能政策目标。对于那些影响中国经济长远发展的重要 领域, 政府可以通过法律法规的制定, 以法律手段来强制 微观企业在法律允许的范围内来调整自己的部分经济行 为。

\section{2. 完善企业的市场退出机制}

加强企业自行注销制度，充分利用企业进入破产程序 以及利用资本退出机制等市场化手段的方式让市场主体 发挥自身调整功能, 从而达到淘汰和化解过剩产能的目的, 这是化解中国过剩产能和企业的重要途径。在完善市场化 化退出机制方面, 中国需要进一步丰富企业登记、注销、 终止或者破产以及资本退出的渠道、降低成本、简化程序。 便捷顺畅的市场退出机制有助于市场微观主体在较短时 间内进行自我调整，使过剩的资金和设备等资源撤出产能 过剩领域, 达到资源配置优化。中国要学习西方发达国家 的经验, 完善降低注销成本、完善破产程序以及建立资本 多渠道退出机制等政策内容, 帮助过剩产能企业顺利退出, 加快过剩产能企业的迭代和更新能力, 这对于中国具有重 要的借鉴意义。

\section{3. 加强人口户籍改革和完善失业保险制度}

从国际经验来看, 处理就业问题主要有三种思路: 第 一, 采取短期资金补助和失业保险金等方式对失业者提供 必要的资金救助，从而维持其在失业期间的日常生活; 第 二, 加强对失业人员和过剩产能员工的职业培训。最重要 的是, 完善失业保险制度, 如扩大失业保险制度覆盖范围, 降低参保条件限制; 加大就业保险再投入; 提高就业保险 制度缴费率, 实施各种手段来促进员工的再就业, 建议成 立就业保障中心、增加工作技能计划覆盖面、发挥再就业 培训项目和求职津贴项目的作用等。

\section{4. 完善地方官员考核机制}

地方政府对处置过剩企业不积极有两个原因：第一： 处置过剩产能和企业会在短期内拖累GDP, 从而影响地方 的官员的政绩考核。第二：处置过剩产能和企业会短期造 成冲击就业, 影响地方的社会稳定。第三: 处置过剩产能 和企业会减少地方财政收入, 降低地方税收。这导致地方 政府有充分动力去补贴过剩企业。

地方政府是处理和消化过剩产能和企业的最终的执 行官员，所以有必要充分激发地方政府官员的积极性。首 先, 考虑弱化对GDP的简单大考核, 加强官员考核机制从 GDP导向到绿色GDP效率导向, 必要情况下把重点行业去 产能的目标明确写入地方政府工作报告, 从而用量化指标 的方式促使地方落实淘汰落后产能的目标。

\section{5. 提高技术，环保，能耗等行业准入门槛}

十三五提出中国提出了绿色发展的理念, 说明中国对 环境保护的重视, 在我国环境持续恶化的情况下, 正好可 以严格方式来要求企业提高环保标准, 把污染严重的过剩 企业列入黑名单。

关停过剩产能企业必须要设定明确而严格的标准。对 于产能过剩的传统行业, 提高准入标准一方面可以阻止生 产规模较小、生产效率较低的小企业继续进入, 避免进一 步加剧行业间竞争和产能的过剩，另一方面可以根据这个 标准, 对不达标的过剩产能企业进行关停, 明确去产能的 规则, 引导过剩产能企业有序退出。

\section{6. 促进产能升级, 唤醒创新动力}

随着技术发展和行业竞争加剧, 过剩产能企业具有对 产能进行更新换代、提高生产率的动机。

对于过剩产能企业而言, 过快过多地淘汰落后产能, 会对企业生产能力造成较大冲击, 若超出过剩产能企业承 受能力, 甚至会导致企业破产。

首先应将淘汰落后产能和增加先进新产能进行捆绑, 可以短期内避免去产能对过剩企业造成过于剧烈的冲击, 在循序渐进去产能的同时实现产能存量的升级。企业作为 经济活动微观主体, 也会积极努力的提高自身创新能力, 寻找新的利润增长点。

\section{7. 从现实出发, 有序化解是最优路径}

产能过剩的行业, 在地方经济发展中是大多是支柱产 业, 是GDP增速、就业岗位和税收收入的大户。如果短期 采取急剧的去产能政策, 必然会带来一系列问题, 如地方 经济硬着陆、大规模失业以及银行不良贷款的大幅增加等 等。目前, 稳定与发展、防风险仍然是是地方政府考虑的 主要因素。

如果只是采取市场手段去产能倒逼, 效果会比较缓慢。 在去产能的过程中, 企业之间的博亦行为非常普遍并且严 重。目前，无论是国有企业还是民营企业，对中国未来的 经济前景仍然抱有乐观积极的预期, 都希望等待中国经济 的回暖。 
所以稳步推进、有序化解是最优路径选择。关于供给 侧结构性改革和去过剩产能, 市场希望尽快把所有落后产 能清理完毕, 从而让经济进入合理轨道, 这反映了市场对 供给侧改革的迫切要求。但在“经济新常态”大背景下和经 济下行压力的关键时期, 稳定与发展是一条主线。所以避 免发生系统性的经济危机和金融危机，仍然是中国政府制 定去产能政策的重要关注点。因此, 无论是从政府角度, 还是从过剩产能企业角度, 或者从金融中介机构角度, 急 剧的、一刀切的去产能政策不符合大家利益, 仍然建议进 度上放缓, 注重从结构性的现实问题出发, 稳步并且循序 渐进式的方式来推进。

\section{致谢}

感谢课题《城市创新生态系统的的效率和健康评价》 资金支持，感谢张永老师提供的研究思路，感谢中关村企 业家顾问委员会提供了很重要的研究数据和相关企业资 料, 感谢朱顺南博士的校对和建议。

\section{参考文献}

[1] 张杰, 宋志刚. 供给侧结构性改革中“去产能”面临的困局、 风险及对策 [J]. 河北学刊, 2016, (04):123-129。

[2] 王元地, 杨雪, 胡园园, 李艳佳. “供给侧改革”解读及其 政策影响下的企业实践 $[\mathrm{J}]$. 中国矿业大学学报(社会科学 版), 2016,(03):48-59。

[3] 任泽平, 张庆昌. 供给侧改革去产能的挑战、应对、风险 与机遇 $[J]$. 发展研究, 2016, (04):7-13。

[4] 廖清成, 冯志峰. 供给侧结构性改革的认识误区与改革重 点 $[\mathrm{J}]$. 求实, 2016, (04):54-60。

[5] 贾康, 苏京春. 论供给侧改革[J]. 管理世界, 2016, (03):1-24。

[6] 萨伊. 政治经济学概论[M]. 北京: 商务印书馆, 2010. [2]。
[7] 王东. 西方宏观经济学的发展演变及其启示 $[\mathrm{J}]$. 南开经济 研究, 1997(2):50-55。

[8] 约翰·梅纳德·凯恩斯. 就业、利息和货币通论 $[\mathrm{M}]$. 北京: 商务印书馆, 2005。

[9] 李智, 原锦风. 基于中国经济现实的供给侧改革方略 [J]. 价 格理论与实践, 2015, (12):12-17。

[10] 胡鞍钢, 周绍杰, 任皓. 供给侧结构性改革一一适应和引 领中国经济新常态 [J]. 清华大学学报(哲学社会科学版), 2016, (02):17-22+195。

[11] 韩国高. 现阶段我国工业产能过剩及去产能的形势分析 [J]．科技促进发展，2015, (05):625-630。

[12] 习近平. 一手抓结构改革一手抓补民生短板 [N]. 解放日报, 2016-03-09。

[13] 张杰, 翟福昕. 多重目标下宏观调控思路调整与政策匹配 [J]. 改革, 2014, (09):42-51。

[14] 陶一桃. 需求与供给之间的选择——供给学派对扩大 “内需” 的启示 $[J]$. 学习与探索, 2000, (03):12-16。

[15] 胡代光. 剖析新自由主义及其实施的后果 $[\mathrm{J}]$. 当代经济研 究, 2004, (02):17-21+73。

[16] 廖清成, 冯志峰. 供给侧结构性改革的认识误区与改革重 点 $[J]$. 求实, 2016, (04):54-60。

[17] 李智, 原锦风. 基于中国经济现实的供给侧改革方略 [J]. 价 格理论与实践, 2015, (12):12-17。

[18] 胡鞍钢, 周绍杰, 任皓. 供给侧结构性改革一适应和引 领中国经济新常态 $[\mathrm{J}]$. 清华大学学报(哲学社会科学版), 2016, (02):17-22+195。

[19] 蔡之兵. 地方政府去产能效果与特征: 2006 2014年[J]. 改 革, 2016, (10):43-53。

[20] 邹蕴涵. 我国产能过剩现状及去产能政策建议 [J]. 发展研 究, 2016, (07):17-21。 